\title{
Prevalence and Factors Associated with Overweight and Obesity among Adolescents in Schools in Benin in 2016
}

\section{Olga Agbohoui Houinato ${ }^{*}$, Alphonse Kpozehouen ${ }^{2}$, Benjamin Hounkpatin ${ }^{3}$, Kévin Yann Gbédji1, Hélène Robin1, Carmelle Mizéhoun-Adissoda", Fernand Guédou4, Dismand Stéphan Houinato', René Xavier Perrin ${ }^{3}$}

\author{
${ }^{1}$ Epidemiologic Laboratory for Chronic and Neurological Diseases (LEMACEN), Faculty of Health Sciences, University of \\ Abomey Calavi, Cotonou, Benin \\ ${ }^{2}$ Regional Institut of Public Healt. (IRSP), University of Abomey Calavi, Cotonou, Benin \\ ${ }^{3}$ Centre Hospitalier Universitaire de la Mère et de l'Enfant Lagune (CHU MEL), Faculty of Health Sciences, University of Abomey \\ Calavi, Cotonou, Benin \\ ${ }^{4}$ Health Center of Sexually Transmitted Infections (DIST), Health Center of Cotonou1, Cotonou, Bénin \\ Email: ${ }^{*}$ oagbohoui@gmail.com
}

How to cite this paper: Houinato, O.A., Kpozehouen, A., Hounkpatin, B., Gbédji, K.Y., Robin, H., Mizéhoun-Adissoda, C., Guédou, F., Houinato, D.S. and Perrin, R.X. (2019) Prevalence and Factors Associated with Overweight and Obesity among Adolescents in Schools in Benin in 2016. Open Journal of Epidemiology, 9, 213-242. https://doi.org/10.4236/ojepi.2019.93018

Received: May 23, 2019

Accepted: August 9, 2019

Published: August 12, 2019

Copyright $\odot 2019$ by author(s) and Scientific Research Publishing Inc. This work is licensed under the Creative Commons Attribution International License (CC BY 4.0).

http://creativecommons.org/licenses/by/4.0/ (c) (i) Open Access

\begin{abstract}
Introduction Overweight and obesity are considered to be global public health concerns. The objective was to estimate the prevalence of overweight and obesity and the associated factors. Methods This was a cross-sectional study conducted in 2016 and involving 3968 adolescents of 10 to 19 years from 40 secondary schools in Benin. Participants were selected using a 2-level random sampling technique. Data were collected through a self-administered questionnaire and were analyzed using Epi Info and Stata softwares. Associated factors were investigated by a logistic regression. Results Mean age was $16.54 \pm 0.04$ years and sex ratio was 1.16. The prevalence of overweight was $8.1 \%$ and that of obesity was $1.6 \%$. Associated risk factors were female gender, sedentary lifestyle, consumption of sugary and carbonated beverages. Consumption of fruits and vegetables, regular physical activity, age over than 15 years were protective factors. Conclusion Overweight and obesity among school adolescents are increasing in Benin. The establishment of a school nutrition program and the promotion of regular physical activity should contribute to reducing their prevalence.
\end{abstract}

\section{Keywords}

Prevalence, Overweight, Obesity, Adolescent, School

Environment 


\section{Introduction}

The stable economic development of a country depends on the level of education, the state of health and the optimal well-being of adolescents and young people.

Childhood and adolescence are recognized as periods of learning about health practices and behaviors, particularly in nutrition. Adolescence is the most important period of health. It is undermined by many health problems including overweight and obesity. The World Health Organization (WHO) considers adolescence to be the period of growth and human development that is between childhood and adulthood, between 10 and 19 years of age. Overweight and obesity are serious public health concerns to adolescents.

In fact, overweight and obesity in an adolescent, later predispose him to chronic diseases such as cardiovascular diseases, diabetes, chronic respiratory diseases and cancers [1]. Other consequences of obesity are psychological effects and social stigma faced by obese adolescents, which can have serious consequences for mental and physical health [2].

Some factual data shows that the school environment influences the consumption of foods and is likely to promote unhealthy eating habits that promote the onset of obesity among students [3]. Besides eating habits, these statuses are as well conditioned by factors such as the practice of physical activity and the involvement of parents, as reported in some studies in developed countries [4].

In addition, the prevalence of overweight and obesity among adolescents has increased steadily in the different age groups and in most countries in the past decades [5]. Thus, worldwide, in 2010, about 42 million children were overweight with 35 million living in developing countries [6]. The prevalence of overweight and obesity among children and youth is increasing in emerging countries in Africa and Asia [7].

Overweight and obesity in adolescents, formerly associated with wealth and developed countries [8] [9], also affect developing countries. In sub-Saharan Africa, among school-aged adolescents, the prevalence of overweight and obesity varies from one country to another. For example, in Nigeria in 2012, 9.7\% of adolescents were overweight and [10] while in Senegal in 2011, 9.7\% were obese [11].

Although several studies are being conducted in Western countries on the subject, this is not the case in Africa where the focus is mainly on communicable diseases such as malaria and HIV/AIDS.

In Benin, the nationwide survey of school-based student health, conducted in 2009 in the framework of the Global School-based Student Health Survey (GSHS) showed a prevalence of $8.8 \%$ for overweight and $0.4 \%$ for obesity [12]. But since then, no further studies have been conducted in the area to provide updated information for better targeted interventions.

It is therefore to contribute to filling this gap in strategic information that the present study was conducted with the objectives of estimating the prevalence of 
overweight and obesity and identifying the associated factors among school adolescents in Benin.

\section{Methodology}

\subsection{Description of the Survey and the Study Population}

We analyzed data from the national survey on the current status and factors associated with adolescent health in schools in Benin in 2016. This was a cross-sectional study targeting 10 to 19 -year-olds children of both sex and enrolled from first to seventh (final) grades of secondary school. The number of subjects required was calculated by the Schwartz formula and was 3841 . The sampling was conducted with the technical support of CDC Atlanta, using a 2-degree random sampling technique with a probability proportional to the size of the schools and classes.

The first level consisted in selecting 40 out of 1494 public and private secondary schools, with a probability proportional to the size of the institutions. At the second level, within each selected institution, a census of all classes was conducted. The choice of classes to be investigated was randomly made from a list of random numbers, pre-established and made available by CDC Atlanta and WHO. This list of numbers varied from a school to another. The number of classes to be surveyed per institution was proportional to the total number of classes available in these selected institutions. Finally, all adolescents of eligible classes present during the survey were included in the study.

The data collection tool was an adapted WHO questionnaire that included demographic and foods behavior data (Annex 1). The weight of each teenager was measured to the nearest $0.1 \mathrm{~kg}$, using an electronic scale (model $753 \mathrm{E}$, Seca, Hamburg, Germany). The height was measured to the nearest $0.1 \mathrm{~cm}$, in a standing position with a SECA height measure device.

\subsection{Variables}

\subsubsection{Dependent Variable}

The dependent variable was the Body Mass Index (BMI) defined using height and weight. The BMI of students was ranked using the WHO growth reference for school-aged children and adolescents by age and sex. Thus, the $\mathrm{Z}$ scores for BMI for age were generated, using the WHO "Anthroplus" software [13].

In accordance with the WHO classification, the BMI was categorized in four modalities: adolescents who had a BMI less than $-2 \mathrm{SD}(<-2 \mathrm{SD})$ for age and sex were considered to be thin and were classified as underweight; those with a BMI between $-2 \mathrm{SD}$ and $1 \mathrm{SD}(-2 \mathrm{SD} \leq \mathrm{BMI} \leq 1 \mathrm{SD})$ were classified as normal; adolescents who had a BMI between 1SD and 2SD (1SD $<$ BMI $\leq 2 \mathrm{SD})$ were classified as overweight while those with a BMI greater than $2 \mathrm{SD}$ (BMI $>2 \mathrm{SD}$ ) were classified as obese. But for the sake of convenience in the statistical analysis, the dependent variable was further categorized into three main modalities by grouping together the normal and underweight modalities which constituted the reference 
modality ("normal") in the polytomic regression.

\subsubsection{Independent Variables}

The independent variables were age, gender, areas of residence, class attended, type of school (public or private), regular pratice of physical activity (exercise for at least 60 minutes a day and at least 3 days a week), consumption of at least five servings of fruits and vegetables, sedentary lifestyle (staying in a sitting position for more than four hours a day), consumption of sugary and carbonated beverages.

\subsection{Data Analysis}

The data were entered with the Excel software and analyzed using the STATA 13.0 software. The qualitative variables were estimated in proportion with their $95 \%$ confidence intervals $(95 \% \mathrm{CI})$ and the quantitative ones in means followed by \pm standard deviation (SD).

Associations between qualitative variables were studied using the Pearson Chi2 test. The strength of the associations between the dependent variable ("BMI") and the independent variables was assessed by calculating Odds Ratios (OR) followed by their 95\% CI. The "overweight" and "obese" modalities of the dependent variable "BMI" were compared to the "normal" (reference) modality.

A polytomous logistic regression was used to evaluate the influence of the explanatory variables on the BMI. All statistically significant variables at a p-value $<0.20$ in the univariate analysis were included in the multivariate models and a stepwise modeling procedure was adopted to select the variables that were used to build the final model. Only variables with a p-value of less than 0.05 have been retained in the final model. To take into account the effect of the sampling procedure used, we weighted all our analyses. The adequacy of the model was verified using the Hosmer-Lemshow test.

\subsection{Ethical Consideration}

The protocol was approved by the Institutional Research Ethics Committee of the Institute of Applied Biological Sciences (CER-ISBA). Legally major students (18 years or older) provided their informed consent while the minor ones (less than 18 years) provided their informed assent along with their parents informed consent. All data were anonymous.

\section{Results}

\subsection{Sociodemographic, Behavioral and Psychological Characteristics of Participants}

Our analyses included 3968 school adolescents, which corresponds to a response rate of $78.00 \%$ of the sampled population.

Table 1 shows the distribution of adolescents according to general characteristics. The average age of the 3968 adolescents included in the study was $16.54 \pm$ 0.04 years and the sex ratio male/female of 1.16 . They lived mainly in urban 
areas $(60.5 \%)$ and $68.9 \%$ were in public schools. More than one in two teens had lived with their parents in the last 30 days prior to the survey (Figure 1).

The proportions of adolescents who consumed fast food or sugary and carbonated beverages were $38.6 \%$ and $34.9 \%$, respectively while $56.4 \%$ had regular practice of physical activity (Table 1 ).

The distribution of adolescents according to the psychological variables shows that $14.3 \%$ of the respondents had often felt lonely in the last twelve months preceding the survey; $20.8 \%$ were often anxious during the same period and $15.9 \%$ thought of a suicide plan (Table 1 ).

\subsection{Prevalence of Overweight and Obesity among Participants}

In our sample, overweight adolescents accounted for 8.1\% (CI 95\%: 7.02 - 9.25) and obese adolescents for 1.6\% (CI 95\%: 1.06\% - 2.04\%). This corresponded to 9.7\% (CI 95\%: 8.48\% - 10.90\%) of excess in body weight.

\subsection{Factors Associated with Overweight and Obesity}

Table 2 summarizes the factors associated with the prevalence of overweight and obesity in univariate and multivariate analyses.

The univariate analysis revealed that girls were more likely to be overweight $(\mathrm{OR}=2.8,95 \% \mathrm{CI} 2.09-3.75)$ or obese $(\mathrm{OR}=3.91,95 \% \mathrm{CI} 2.01-7.61)$ than boys. Adolescents over the age of 15 were less likely to be overweight $(\mathrm{OR}=0.26$, 95\% CI: $0.18-0.36)$ or obese $(\mathrm{OR}=0.19,95 \% \mathrm{CI}: 0.10-0.37)$. Attending a public school was a protective factor for overweight $(\mathrm{OR}=0.65,95 \%$ CI $0.47-0.88)$ and obesity $(\mathrm{OR}=0.28,95 \%$ CI $0.15-0.52)$, compared to private schools. Adolescents who consumed sugary and carbonated beverages were more likely to be overweight $(\mathrm{OR}=1.59,95 \% \mathrm{CI}: 1.17-2.15)$ than those who did not; the same was true for those living in urban areas (OR $=1.56,95 \% \mathrm{CI}: 1.08-2.27)$ compared to those living in rural areas. Sedentary adolescents were more likely to be overweight $(\mathrm{OR}=2.29,95 \% \mathrm{CI}: 1.60-3.28)$ or obese $(\mathrm{OR}=6.22,95 \% \mathrm{CI}: 3.24$ 11.93).

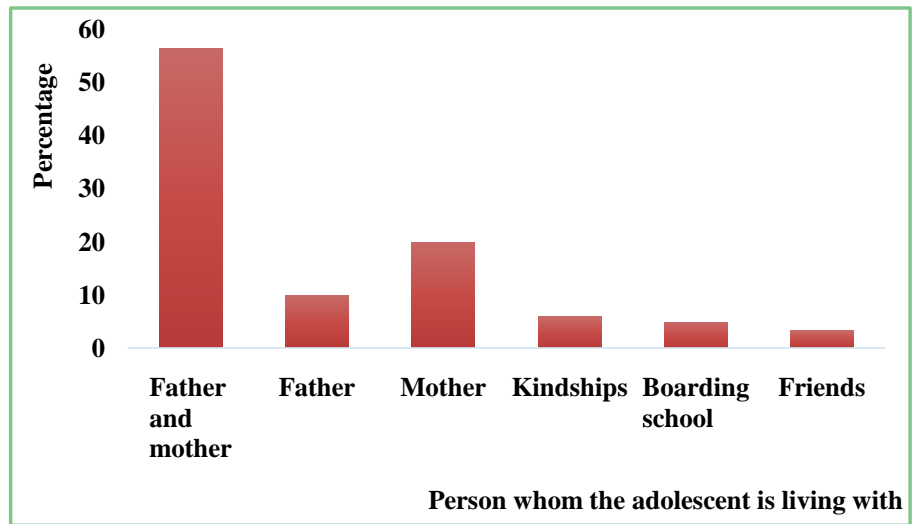

Figure 1. Distribution of school adolescents according to the person with whom they lived the last 30 days preceding the survey in Benin in 2016. 
Table 1. Distribution of school adolescents by socio-demographic, behavioral and psychological characteristics in Benin in 2016.

\begin{tabular}{|c|c|c|}
\hline & Frequencies & Weighted percentage (\%) \\
\hline \multicolumn{3}{|c|}{ Demographic characteristics } \\
\hline \multicolumn{3}{|c|}{ Age (Years) $N=3968$} \\
\hline$<15$ ans & 1335 & 13.3 \\
\hline$\geq 15$ ans & 2633 & 86.7 \\
\hline \multicolumn{3}{|l|}{$\operatorname{Sex} N=3953$} \\
\hline Male & 2127 & 72.9 \\
\hline Female & 1826 & 27.1 \\
\hline \multicolumn{3}{|c|}{ Areas of residence $\mathrm{N}=3190$} \\
\hline Rural & 918 & 39.5 \\
\hline Urban & 2272 & 60.5 \\
\hline \multicolumn{3}{|c|}{ Class attended $\mathrm{N}=3968$} \\
\hline $1^{\text {st }}$ & 653 & 0.3 \\
\hline $2^{\text {nd }}$ & 794 & 0.2 \\
\hline $3^{\text {rd }}$ & 915 & 30.1 \\
\hline $4^{\text {th }}$ & 657 & 30.7 \\
\hline $5^{\text {th }}$ & 408 & 12.4 \\
\hline $6^{\text {th }}$ & 174 & 11.7 \\
\hline $7^{\text {th }}$ & 367 & 14.6 \\
\hline \multicolumn{3}{|c|}{ Type of school N = 3953} \\
\hline Public & 2928 & 68.9 \\
\hline Private & 1025 & 31.1 \\
\hline \multicolumn{3}{|c|}{ Department $(\mathrm{N}=3918)$} \\
\hline Alibori & 434 & 17.8 \\
\hline Atacora & 305 & 8.9 \\
\hline Atlantique & 489 & 9.7 \\
\hline Borgou & 549 & 14.8 \\
\hline Collines & 119 & 4.0 \\
\hline Couffo & 57 & 0.1 \\
\hline Donga & 86 & 2.5 \\
\hline Littoral & 330 & 7.6 \\
\hline Mono & 330 & 7.1 \\
\hline Ouémé & 571 & 11.1 \\
\hline Plateau & 122 & 3.2 \\
\hline Zou & 551 & 12.4 \\
\hline
\end{tabular}




\section{Continued}

\section{Behavioral characteristics}

Sedentary lifestyle $\mathrm{N}=3968$

$\begin{array}{lll}\text { No } & 3417 & \mathbf{8 7 . 6} \\ \text { Yes } & 551 & 12.4\end{array}$

Consumption of at least 5 servings of fruits and vegetables $\mathrm{N}=3960$

$\begin{array}{lrr}\text { No } & 3642 & 94.3 \\ \text { Yes } & 318 & 5.7\end{array}$

Sugar and soft beverages consumption $\mathrm{N}=3958$

No

2222

65.1

Yes

1736

34.9

Fast food dish consumption $\mathrm{N}=3947$

$\begin{array}{ccc}0 \text { day } & 2253 & 61.4 \\ 1 \text { or } 2 \text { days } & 1142 & 27.4 \\ 3 \text { days and more } & 552 & 11.2\end{array}$

Regular Practice of Physical Activity N $=3955$

$\begin{array}{lll}\text { No } & 1884 & 43.6 \\ \text { Yes } & 2071 & \mathbf{5 6 . 4}\end{array}$

Psychological characteristics

Solitude $\mathbf{N}=3950$

$\begin{array}{lcc}\text { No } & 3432 & 85.7 \\ \text { Yes } & 518 & 14.3\end{array}$

Anxiety N $=3948$

$\begin{array}{lll}\text { No } & 3277 & 79.2 \\ \text { Yes } & 671 & 20.8\end{array}$

Suicide plan $\mathrm{N}=3939$

$\begin{array}{lll}\text { No } & 3271 & 84.1 \\ \text { Yes } & 668 & 15.9\end{array}$

Have close friends $\mathrm{N}=3951$

$\begin{array}{lrr}\text { No } & 452 & 10.7 \\ \text { Yes } & 3499 & 89.3\end{array}$

Relationship with parents/guardians N $=3929$

$\begin{array}{lll}\text { No } & 2375 & 64.2 \\ \text { Yes } & 1554 & 35.8\end{array}$


Table 2. Association between overweight, obesity and independent variables among school adolescents in Benin in 2016: univariate and multivariate analyses.

\begin{tabular}{|c|c|c|c|c|}
\hline & \multicolumn{2}{|c|}{ Univariate analysis OR (IC 95\%) } & \multicolumn{2}{|c|}{ Multivarate analysis OR (IC 95\%) } \\
\hline & Overweight & Obesity & Overweight & Obesity \\
\hline \multicolumn{5}{|c|}{ Sex } \\
\hline Male & 1 & 1 & 1 & 1 \\
\hline Female & $2.8(2.09-3.75)^{* * *}$ & $3.91(2.01-7.61)^{* * *}$ & $2.52(2.47-2.57)^{\star \star \star}$ & $3.36(3.23-3.50) * \star \star x$ \\
\hline \multicolumn{5}{|c|}{ Age (Years) } \\
\hline$<15$ ans & 1 & 1 & 1 & 1 \\
\hline$\geq 15$ ans & $0.26(0.18-0.36)^{\star * *}$ & $0.19(0.10-0.37)^{\star * \star}$ & $0.27(0.26-0.28)^{\star * *}$ & $0.18(0.17-0.18)^{\star * *}$ \\
\hline \multicolumn{5}{|c|}{ Regular Practice of Physical Activity } \\
\hline No & 1 & 1 & 1 & 1 \\
\hline Yes & $0.67(0.50-0.91)^{\star *}$ & $0.51(0.26-0.97)^{*}$ & $0.82(0.80-0.83)^{\star \star \star}$ & $0.66(0.63-0.69)^{\star * *}$ \\
\hline \multicolumn{5}{|c|}{ Sedentary lifestyle } \\
\hline No & 1 & 1 & 1 & 1 \\
\hline Yes & $2.29(1.60-3.28)^{* \star *}$ & $6.22(3.24-11.93) * * *$ & $1.07(1.04-1.10)^{\star * \star}$ & $1.17(1.11-1.24)^{* *}$ \\
\hline \multicolumn{5}{|c|}{ Consumption of at least 5 servings of fruits and vegetables } \\
\hline No & 1 & 1 & 1 & 1 \\
\hline Yes & $0.46(0.23-0.90)^{\star}$ & $0.45(0.11-1.82)$ & $0.36(0.34-0.38)^{\star \star \star}$ & $0.33(0.29-0.37)^{\star * \star}$ \\
\hline \multicolumn{5}{|c|}{ Sugar and soft beverage consumption } \\
\hline No & 1 & 1 & 1 & 1 \\
\hline Yes & $1.59(1.17-2.15)^{\star *}$ & $1.77(0.93-3.35)$ & $1.46(1.44-1.49)^{\star * \star}$ & $1.53(1.47-1.60)^{* * *}$ \\
\hline \multicolumn{5}{|c|}{ Class attended (Grade) } \\
\hline 1 st & 1 & 1 & 1 & 1 \\
\hline $2^{\text {nd }}$ & $7.47(1.50-37.27)^{*}$ & $2.39(0.93-6.15)$ & $4.78(3.57-6.41)^{\star * *}$ & $1.33(0.75-2.34)$ \\
\hline $3 \mathrm{rd}$ & $2.71(1.30-5.67)^{\star *}$ & $1.37(0.55-3.45)$ & $3.33(2.58-4.30)^{\star * \star}$ & $1.85(1.21-2.81)^{\star *}$ \\
\hline 4 th & $2.46(1.16-5.19) *$ & $1.66(0.65-4.25)$ & $4.21(3.26-5.44)^{* * *}$ & $3.62(2.38-5.51)^{* * *}$ \\
\hline 5 th & $2.66(1.22-5.80)^{*}$ & $0.93(0.27-3.21)$ & $5.84(4.52-7.54)^{* * *}$ & $2.80(1.83-4.28) * * *$ \\
\hline 6th & $0.91(0.30-2.72)$ & $0.65(0.11-3.65)$ & $2.09(1.62-2.71)^{\star \star \star}$ & $2.17(1.42-3.33)^{\star * *}$ \\
\hline 7th & $1.57(0.69-3.60)$ & $0.75(0.23-2.47)$ & $3.62(2.80-4.68)^{\star \star \star}$ & $2.48(1.62-3.79)^{\star * *}$ \\
\hline \multicolumn{5}{|c|}{ Fast food dish consumption } \\
\hline 0 day & 1 & \multicolumn{3}{|l|}{ 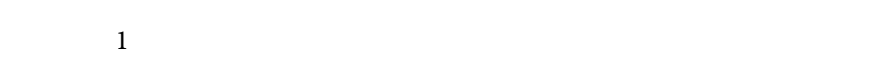 } \\
\hline 1 to 2 days & $1.13(0.81-1.58)$ & \multicolumn{3}{|l|}{$1.08(0.51-2.26)$} \\
\hline 3 days and more & $0.92(0.57-1.48)$ & \multicolumn{3}{|l|}{$0.85(0.29-2.50)$} \\
\hline \multicolumn{5}{|c|}{ Type of school } \\
\hline Private & 1 & 1 & & \\
\hline \multirow[t]{2}{*}{ Public } & $0.65(0.47-0.88)^{\star *}$ & $0.28(0.15-0.52)^{\star * *}$ & & \\
\hline & & Areas of Residence & & \\
\hline Rural & 1 & 1 & & \\
\hline
\end{tabular}




\section{Continued}

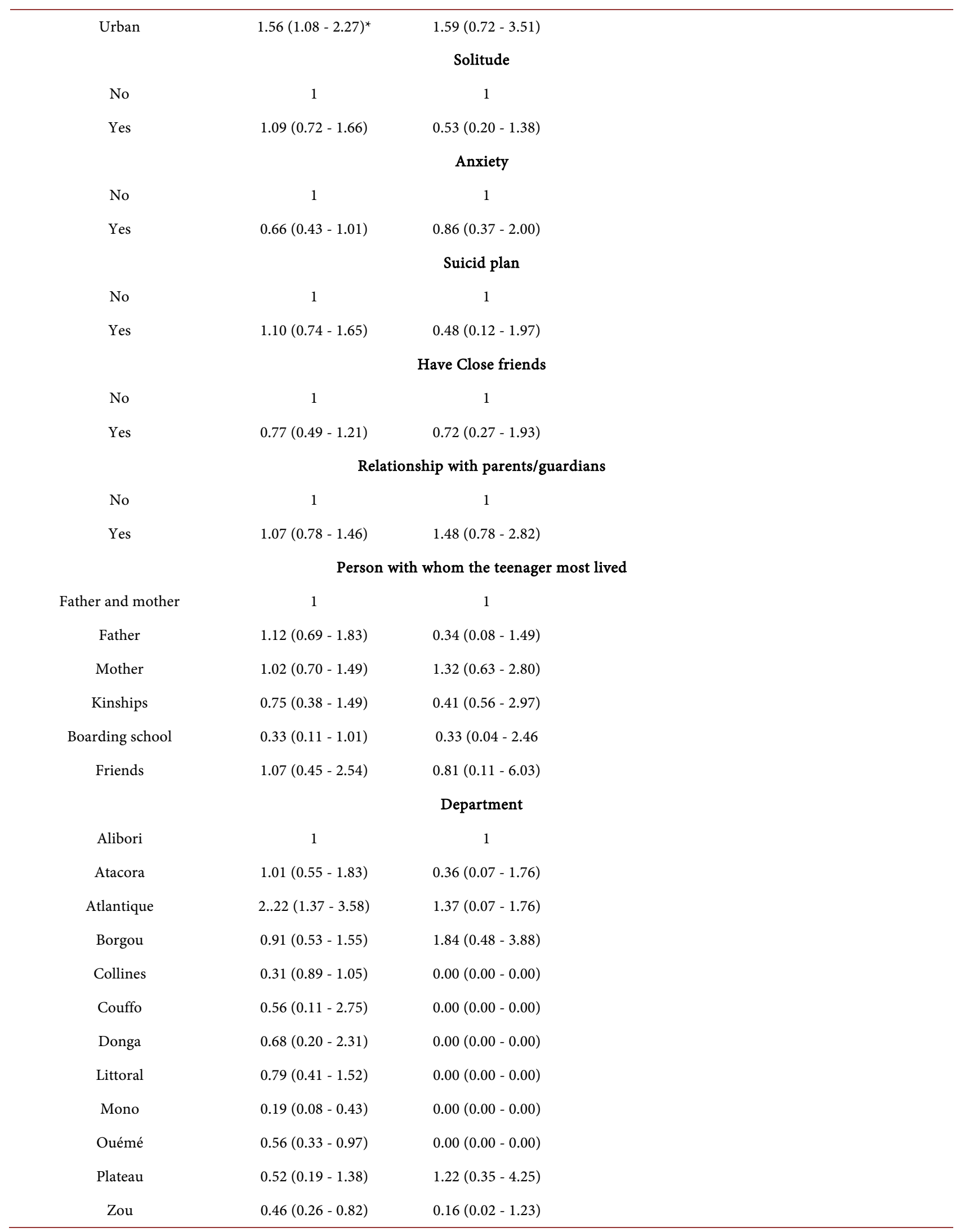

${ }^{*}=\mathrm{p}<0.05^{* *}=\mathrm{p}<0.01^{* * *}=\mathrm{p}<0$. 
The multivariate analysis revealed that girls were significantly more likely to be overweight ( $\mathrm{OR}=2.52$, CI 95\%: 2.47 - 2.57) or obese ( $\mathrm{OR}=3.36$, CI 95\%: 3.23 - 3.50) than boys. Adolescents older than 15 years were less likely to be overweight $(\mathrm{OR}=0.27$, CI 95\%: $0.26-0.28)$ or obese $(\mathrm{OR}=0.18$, CI 95\%: $0.17-0.18)$ than those under 15 years of age. Consumption of at least 5 servings of fruits and vegetables per day ( $\mathrm{OR}=0.36$, CI 95\%: $0.34-0.38$ for overweight and $\mathrm{OR}=0.33$ CI 95\%: $0.29-0.37$ for obesity) and regular pratice of physical activity (OR = 0.82, CI 95\%: $0.80-0.83$ for overweight and OR $=0.66$ CI 95\%: $0.63-0.69$ for obesity) were protective factors against overweight and obesity, unlike sugary and carbonated beverages whose consumption exposed adolescents to almost 50\% higher risk ( $\mathrm{OR}=1.46, \mathrm{CI} 95 \%: 1.44-1.49)$. Sedentary adolescents were more likely to be overweight $(\mathrm{OR}=1.07$, CI $95 \%: 1.04-1.10)$ or obese $(\mathrm{OR}=$ 1.17, CI 95\%: 1.11 - 1.24).

\section{Discussion}

\subsection{Prevalence}

In this study, the prevalence of obesity was estimated at 1.6\% (CI 95\%: 1.06\% 2.04\%) and that of overweight at 8.1\% (CI 95\%: 7.02 - 9.25).

Some authors have found prevalence of overweight and obesity of the same order of magnitude as ours. For example, Musa \& al. found an overweight prevalence of 9.7\% in Nigeria among school-aged adolescents in 2012 [10]. In 2009, the national school health survey (GSHS) in Benin reported a prevalence of $8.8 \%$ for overweight [12]. In Togo in 2010, Djadou \& al, reported a prevalence of obesity of $1.7 \%$ [14]. In Ghana, in 2014, Manyanga \& al. found a prevalence of $8.7 \%$ for overweight and of $1.0 \%$ for obesity [15]. The magnitude of overweight in this study may be explained by the nutritional transition taking place in the context of empowerment, which leads to a double nutritional burden [15]. Traditional food tends to disappear in favor of a Western diet consisting mainly of fast food dishes, associated with the consumption of sugary and carbonated beverages and sweet foods. The high prevalence of overweight may also be explained by the fact that in African culture, being overweight is synonymous with wealth and health [15].

Other authors, on the other hand, found higher school prevalence than ours. These include Mantey \& al. who reported a prevalence of $13.6 \%$ among adolescents in Haute-Savoie department of France in 2005 [16]. The prevalence found in schools by Abu Baker NN \& al in 2010 in Jordan for 13 to 16 year-olds and in Brazil by Gudes DP et al. for 6 to 18 year-olds in 2011 were $15.7 \%$ surpoids et 8 , $7 \%$ obesity [17] and $11.1 \%$ et $2.7 \%$ Obesity [18], respectively. Manyanga \& al. reported in 2014 [15] in Egypt a prevalence of 31.4\% for overweight. According to studies conducted in schools by Sebbani M \& al. in Marrakech in 2013, Kramoh \& al in Côte d'Ivoire in 2012, Desalew \& al in Ethiopia in 2017, Faye \& al in Senegal in 2011 and Regaieg \& al in 2015 in Tunisia, the prevalence of obesity was $3.0 \%$ [19] in, $5.0 \%$ [20], 5.8\% [21], 9.3\% [11], 4.4\% [22] respectively, they were all superior to ours. 
Contrarywise, some authors like Regaieg \& al [22] and Benyaich \& al [23] found in schools, lower prevalence of overweight than ours, which were of $6.3 \%$ and $2.0 \%$, respectively. Obesity prevalence lower than ours was also found in the GSHS studies in Benin (0.4\%) [12] and in Malawi (0.8\%) [15] both in 2009.

The observed differences can be explained by the difference in the target populations and sites. Indeed, none of these studies focused on adolescents aged from 10 to 19 like ours and some of them were conducted at the local and regional levels while others were at the national level. The differences could also be explained by the difference in data collection techniques.

\subsection{Associated Factors}

\subsubsection{Sex}

The female predominance observed in school settings among adolescents for overweight in our study was also reported by several other authors in Nigeria, Togo, Ghana, Jordan and India [10] [14] [15] [17] [18] [24]. Concerning obesity, the same observation was made in Nigeria, Togo, Ghana, Côte d'Ivoire and Tunisia [10] [14] [15] [20] [22]. This gender-based difference could be explained, first by the age range of the studied children since, after a pre-pubertal rebound, there is an increase of the fat mass in the girl while that of the boys decreases [22]. At the age of puberty, girls are more likely to develop fat masses related to growth. In fact, adolescent girls have a hormonal predisposition to developing gynoid obesity and are also more sedentary than boys. It could also be explained by the fact that in African households, manual work requiring physical efforts are more frequently assigned to boys than to girls [15].

\subsubsection{Age}

Our results showed that adolescents aged 15 and older were less likely to be overweight and obese than those under 15 years of age. This association has also been reported in Senegal and Nigeria [10] [11]. Manyanga \& al [15] reported a higher risk of obesity or overweight among adolescents under 15 in seven African countries, namely Benin, Djibouti, Egypt, Ghana, Mauritania, Cameroon, Malawi and Morocco [15].

This association with the under-15 age group was explained by the fact that with age, adolescents become more and more sensitive to the mockery of their peers with regard to overweight or obesity. They become more concerned about their body image [25]. They would therefore tend to impose dietary restrictions and/or the practice of physical activity to themselves. By contrast, Manyanga et al in Malawi [15] and the Alsace regional observatory [15] have found an increase in overweight with age.

\subsubsection{Regular Practice of Physical Activity}

In our results, there was a significant association between overweight/obesity and regular physical activity. Indeed, this variable has been shown to be a protective factor for overweight/obesity. The same observation has been made in 
most studies involving adolescents in schools, including those of Bhuiyan \& al. in Bangladesh [24]; Dendana \& al. in 2016 in Tunisia [26]; Badr W \& al. in Tunisia in 2016 [27]; Regaieg \& al. in 2015 in Tunisia [22] and Desalew \& al. in Ethiopia in 2017 [21]. This relationship is biologically expected as physical activities favor the consumption of body fat mass. However, a few numbers of authors like Allam \& al. in Algeria in 2016, did not find this association in their studies [6].

\subsubsection{Daily Consumption of at Least Five Servings of Fruits and Vegetables}

According to our results, consuming at least 5 servings of fruits and vegetables a day was a protective factor for overweight/obesity among teens. Dendana \& al. in 2016 found similar results [26]. This could be explained by the fact that vegetables and fruits consumption makes us so rapidly fed up that we do not eat so much.

On the other hand, other authors have found an increase in overweight with the consumption of fruits and vegetables. This is the case of Badr $\&$ al. in Tunisia in 2016 among adolescents of the general population [27].

\subsubsection{Consumption of Sugary and Carbonated Beverages}

In our study, the consumption of soft drinks was a risk factor for overweight and obesity. This same association was found by Desalew \& al. in Ethiopia in 2017 [21], St-Onge \& al. for overweight [28] and the health monitoring institute in Haute-Savoie [16]. On the other hand, other authors found results contrary to ours. This is Li M \& al [29] for overweigh. This difference could be explained by the difference in study settings.

\subsubsection{Sedentary Lifestyle}

In our study, there was a significant association between overweight/obesity and sedentary lifestyle. In the literature, several authors have made the same observation in school adolescents. These include Regaieg \& al. among school adolescents aged 15 to 18 [22]; Bhuiyan \& al. among adolescents aged 10 to 15 in Bangladesh [24]; Desalew \& al. in Ethiopia in 2017 [21]; the Institute of Public Health Surveillance in Haute-Savoie in France [16]. This could be explained by the modernization of society and the change of social behavior [18], particularly with the exposure of adolescents to new technology [15]. Indeed, teenagers spend a lot of time in front of television and video games [22]. Obesity results from an imbalance between insufficient physical activity and a diet that is too high in calories. Any movement consumes energy and protects against obesity. That is why it is important to move. In addition, these sedentary periods encourage the consumption of important caloric foods (chocolate, chips, peanuts).

On the other hand Dendana \& al. in Tunisia in 2016 [26] did not find an association between the sedentariness and the overweight.

Finally, in our study, we were unable to demonstrate a significant association between fast food consumption, hunger, place of residence, the type of school 
attended (private or public), loneliness, anxiety, trauma, suicide planning, relationship with parents/guardians (benefitting from the parents or guardian's kind attention and listening), having no close friends, the person with whom the teenager lived and overweight.

The differences between the studies cited above and ours regarding associated factors could be partly explained by a lack of power as most of them were of relatively small size. In addition, they were conducted on different age groups and none covered the whole adolescent age range (10 to 19 years), as was the case in our study, and most have been carried out at the local or regional level, making difficult to compare with ours (Table 3(a) \& Table 3(b)).

Table 3. (a) Comparison of the results of studies on the prevalence and associated factors for overweight; (b) Comparison of the results of studies on the prevalence and associated factors for obesity.

(a)

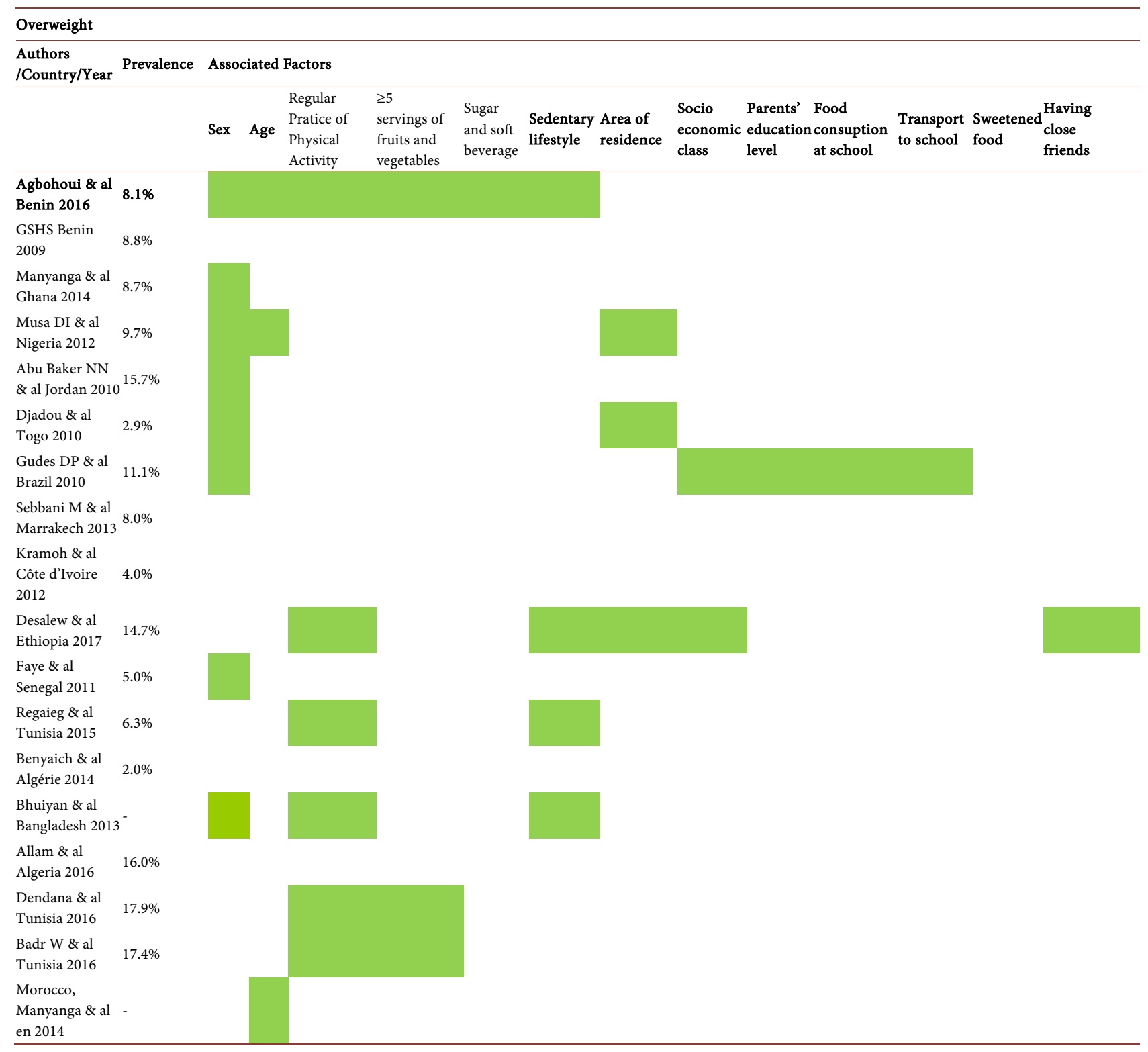


(b)

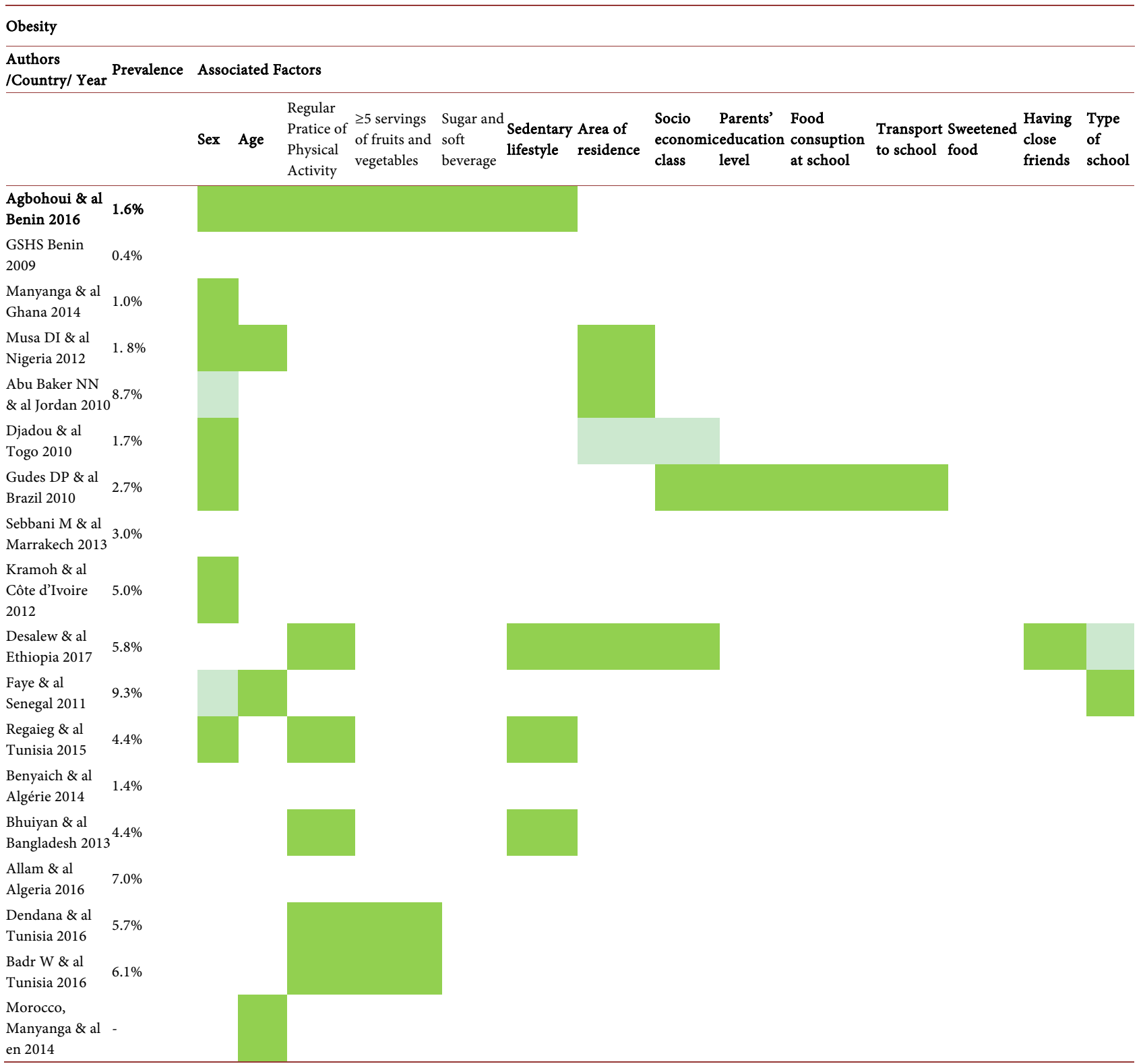

\subsection{Limits}

For logistical reasons, the study could not be extended to university; this could have led to a selection bias, since adolescents are also at university. However, we are certain that most of teenagers are in secondary schools and very few in universities, which could minimize this selection bias.

Family and genetic factors play a role in the development of some obesities but were not taken into account in the present study.

The self-administration of the questionnaire might have induced some information biases due to interviewees negligence or mis-understanding of certain questions. However, we addressed this situation by explaining each question to teens before questionnaire filling. Also, we may have some desirability bias as 
some teenagers may have concealed some bad habits or on the contrary amplify what is perceived as acceptable.

\section{Conclusion}

Our study shows that overweight and obesity among school adolescents are a serious problem in developing countries, particularly in sub-Saharan Africa including Benin. This overweight is significantly related to factors such as gender, age, regular physical activity, consumption of sugary and carbonated beverages, sedentary lifestyle and fruits and vegetables consumption. Considering that the socio-economic development of developing countries depends upon the physical, social and emotional well-being of adolescents, these results argue for taking individual and collective measures to prevent overweight and obesity among school adolescents and thereby the subsequent onset of chronic diseases in their adulthood.

\section{Conflicts of Interest}

The authors declare no conflicts of interest regarding the publication of this paper.

\section{References}

[1] Organisation Mondiale de la Santé (OMS) (2019) Surpoids et obésité de l'enfant. http://www.who.int/dietphysicalactivity/childhood/fr

[2] Tibere, L., Poulain, J.-L., Pacheco da Costa Proenca, R., et al. (2007) Adolescents obèses face à la stigmatisation. Obésité, 2, 173-181. https://doi.org/10.1007/s11690-007-0056-6

[3] Brance, F., Nikogosian, H. and Lobstein, T. (2007) Défi de l'obésité dans la Région européenne de l'OMS et les stratégies de lutte. 68.

[4] Williams, S.L. and Mummery, W.K. (2011) Links between Adolescent Physical Activity, Body Mass Index, and Adolescent and Parent Characteristics. Health Education \& Behavior, 38, 510-520. https://doi.org/10.1177/1090198110385772

[5] Rolland-Cachera, M.-F. (2004) Définitions actuelles de l'obésité de l'enfant. Sang Thrombose Vaisseaux, 16, 187-192.

[6] Allam, O., Oulamara, H. and Nacer Agli, A. (2016) Prévalence et facteurs de risque du surpoids chez des enfants scolarisés dans une ville de l'est algérien (Constantine). Antropo, 35, 91-102.

[7] Lobstein, T. (2007) Prévalence et tendances mondiales (World Federation of Obesity).

[8] Ho, T.F., Yip, W.C., Tay, J.S., et al. (1991) Social Class Distribution of Obese Chinese Children. Journal of the Singapore Paediatric Society, 33, 55-58.

[9] Ji, C.Y. and Cheng, T.O. (2008) Prevalence and Geographic Distribution of Childhood Obesity in China in 2005. International Journal of Cardiology, 131, 1-8. https://doi.org/10.1016/j.ijcard.2008.05.078

[10] Musa, D.I., Toriola, A.L., Monyeki, M.A., et al. (2012) Prevalence of Childhood and Adolescent Overweight and Obesity in Benue State, Nigeria. Tropical Medicine \& International Health: TM \& IH, 17, 1369-1375.

https://doi.org/10.1111/j.1365-3156.2012.03083.x 
[11] Faye, J., Diop, M., Gati, R.O., et al. (2011) Prevalence of Child and Teenage Obesity in Schools in Dakar. Bulletin de la Société de Pathologie Exotique, 104, 49-52. https://doi.org/10.1007/s13149-010-0101-9

[12] Ministère de la Santé (2008) Background-CDC Global School-Based Student Health Survey (GSHS).

[13] World Health Organization (2009) WHO AnthroPlus for Personal Computers Manual Software for Assessing Growth of the World's Children and Adolescents.

[14] Djadou, K.E., Sadzo-Hetsu, K., Koffi, K.S., et al. (2010) Prévalence de l'obésité en milieu scolaire urbain (Togo). Journal de Pédiatrie et de Puériculture, 23, 335-339. https://doi.org/10.1016/j.jpp.2010.06.007

[15] Manyanga, T., El-Sayed, H., Doku, D.T., et al. (2014) The Prevalence of Underweight, Overweight, Obesity and Associated Risk Factors among School-Going Adolescents in Seven African Countries. BMC Public Health, 14, 887. https://doi.org/10.1186/1471-2458-14-887

[16] Mantey, K., Encrenaz, N. and Helynck, B. (2005) Étude du surpoids, de l'obésité et des facteurs associés au surpoids chez les élèves de 6 ème scolarisés dans les collèges publics du département de la Haute-Savoie. Bull Epidemiol Hebd, 52.

[17] Abu Baker, N.N. and Daradkeh, S.M. (2010) Prevalence of Overweight and Obesity among Adolescents in Irbid Governorate, Jordan. Eastern Mediterranean Health Journal, 16, 657-662. https://doi.org/10.26719/2010.16.6.657

[18] Guedes, D.P., Rocha, G.D., Silva, A.J.R.M., et al. (2011) Effects of Social and Environmental Determinants on Overweight and Obesity among Brazilian School Children from a Developing Region. The Revista Panamericana de Salud Pública, 30, 295-302.

[19] Sebbani, M., Elbouchti, I., Adarmouch, L., et al. (2013) Prévalence de l'obésité et du surpoids chez les écoliers de primaire à Marrakech, Maroc. Revue d'Epidémiologie et de Santé Publique, 61, 545-549. https://doi.org/10.1016/j.respe.2013.08.002

[20] Kramoh, K.E., N’goran, Y.N., Aké-Traboulsi, E., et al. (2013) Prevalence of Obesity in School Children in Ivory Coast. Annales de Cardiologie et d’ Angéiologie (Paris), 61, 145-149. https://doi.org/10.1016/j.ancard.2012.04.020

[21] Desalew, A., Mandesh, A. and Semahegn, A. (2017) Childhood Overweight, Obesity and Associated Factors among Primary School Children in Dire Dawa, Eastern Ethiopia; a Cross-Sectional Study. BMC Obesity, 4, 20. https://doi.org/10.1186/s40608-017-0156-2

[22] Regaieg, S., Charfi, N., Elleuch, M., et al. (2015) Obésité, activité physique et temps de sédentarité chez des adolescents scolarisés, âgés de 15 à 18 ans de la ville de Sfax (Tunisie). Pan African Medical Journal, 22, 370. https://doi.org/10.11604/pamj.2015.22.370.6121

[23] Benyaich, K. and Ben Yaich, A. (2017) Etude comparative de la prévalence de surpoids et d'obésité dans 11 pays méditerranéens.

[24] Bhuiyan, M.U., Zaman, S. and Ahmed, T. (2013) Risk Factors Associated with Overweight and Obesity among Urban School Children and Adolescents in Bangladesh: A Case-Control Study. BMC Pediatrics, 13, 72.

https://doi.org/10.1186/1471-2431-13-72

[25] Reilly, J.J. and Kelly, J. (2011) Long-Term Impact of Overweight and Obesity in Childhood and Adolescence on Morbidity and Premature Mortality in Adulthood: Systematic Review. International Journal of Obesity, 35, 891-898. https://doi.org/10.1038/ijo.2010.222 
[26] Dendana, E., Maatoug, J., Sahli, J., et al. (2016) Activité physique et habitudes alimentaires: Quels comportements chez l'adolescent obèse? Annales dEndocrinologie, 77, 536. https://doi.org/10.1016/j.ando.2016.07.875

[27] Badr, W., Ghammam, R., Maatoug, J., et al. (2018) Prévalence de l'obésité et $\mathrm{du}$ surpoids chez les adolescents et association avec les facteurs de risques comportementaux Sousse, Tunisie 2016. Annales d Endocrinologie, 79, 504-505. https://doi.org/10.1016/j.ando.2018.06.1028

[28] St-Onge, M.-P., Keller, K.L. and Heymsfield, S.B. (2003) Changes in Childhood Food Consumption Patterns: A Cause for Concern in Light of Increasing Body Weights. The American Journal of Clinical Nutrition, 78, 1068-1073. https://doi.org/10.1093/ajcn/78.6.1068

[29] Li, M., Dibley, M.J., Sibbritt, D., et al. (2008) Factors Associated with Adolescents' Overweight and Obesity at Community, School and Household Levels in Xi'an City, China: Results of Hierarchical Analysis. European Journal of Clinical Nutrition, 62, 635-643. https://doi.org/10.1038/sj.ejcn.1602757 


\section{Appendix 1: Questionnaire}

2016 BENIN SURVEY ON THE STATE OF THE HEALTH FACILITIES OF ADOLESCENTS IN SCHOOL ENVIRONMENTS

This survey is about your health and the things you do that may affect your health. Students like you all over your country are doing this survey. Students in many other countries around the world also are doing this survey. The information you give will be used to develop better health programs for young people like yourself.

DO NOT write your name on this survey or the answer sheet. The answers you give will be kept private. No one will know how you answer. Answer the questions based on what you really know or do. There are no right or wrong answers.

Completing the survey is voluntary. Your grade or mark in this class will not be affected whether or not you answer the questions. If you do not want to answer a question, just leave it blank.

Make sure to read every question. Check the boxes on your answer sheet that match your answer. When you are done, do what the person who is giving you the survey says to do.

Thanks very much for your help.
1) How old are you?
a) 10 years old
b) 11 years old
c) 12 years old
d) 13 years old
e) 14 years old
f) 15 years old
g) 16 years old
h) 17 years old
i) 18 years old
j) 19 years old
2) What is your sex?
a) Male
b) Female
3) In what grade/class/ standard are you?
a) $1^{\text {st }}$
b) $2^{\text {nd }}$
c) $3^{\text {rd }}$
d) $4^{\text {th }}$
e) $5^{\text {th }}$
f) $6^{\text {th }}$
g) $7^{\text {th }}$
4) In the last 30 days, who did you live with most of the time?
a) Both, my father or guardian and my mother or guardian 

b) Only my father or guardian
c) Only my mother or guardian
d) kinships
e) Internships
f) Friends

The next questions ask about your height and weight,

How tall are you without your shoes on?

ON THE ANSWER SHEET, WRITE YOUR HEIGHT AND WEIGHT

Height $(\mathrm{cm})$ :

How much do you weigh without your shoes on?

Weight (kg):

The next questions ask about what you might eat and drink.

5) During the past 30 days, how many times per day did you usually eat fruit, such as pineapple, mango, apple, papaya, orange, avocado or lemon?

a) I did not eat fruit during the past 30 days

b) Less than one time per day

c) 1 time per day

d) 2 times per day

e) 3 times per day

f) 4 times per day

g) 5 or more times per day

6) During the past 30 days, how many times per day did you usually eat vegetables, such as carrots, cabbage, green vegetables (amaranth, vernonia, basil, black plum ...), tomato, onion, salad, green beans, sweet pepper?

a) I did not eat vegetables during the past 30 days

b) Less than one time per day

c) 1 time per day

d) 2 times per day

e) 3 times per day

f) 4 times per day

g) 5 or more times per day

7) During the past 30 days, how many times per day did you usually drink carbonated soft drinks, such as Coca - cola, Sprite or Tonic or Sweet Ginger juices (do not count sodas without sugar)

a) I did not drink carbonated soft drink during the past 30 days

b) Less than one time per day

c) 1 time per day

d) 2 times per day

e) 3 times per day

f) 4 times per day

g) 5 or more times per day

8) During the past 7 days, on how many days did you eat food from a fast food restaurant, such as Ice Festival, Cafariat, Debonnaire or King of Chawamar? 

a) 0 day
b) 1 day
c) 2 days
d) 3 days
e) 4 days
f) 5 days
g) 6 days
h) 7 days

The next questions ask about cleaning your teeth and washing your hands.

9) During the past 30 days, how many times per day did you usually clean or brush your teeth?

a) I did not clean or brush my teeth during the past 30 days
b) Less than 1 time per day
c) 1 time per day
d) 2 times per day
e) 3 times per day
f) 4 or more times per day
10) During the past 30 days, how often did you wash your hands before eating?
a) Never
b) Rarely
c) Sometimes
d) Most of the time
e) Always

11) During the past 30 days, how often did you wash your hands after using the toilet or latrine?
a) Never
b) Rarely
c) Sometimes
d) Most of the time
e) Always

12) During the past 30 days, how often did you use soap when washing your hands?
a) Never
b) Rarely
c) Sometimes
d) Most of the time
e) Always
13) Is there a drinking water point at the school ?
a) Yes
b) No

14) Is there a place in the school where to wash hands after using the toilet or latrine? 

a) There are no toilets or latrines at school
b) Yes
c) No
15) Are the toilets or latrines in the school clean?
a) There are no toilets or latrines at school
b) Yes
c) No

The next question asks about physical attacks. A physical attack occurs when one or more people hit or strike someone, or when one or more people hurt another person with a weapon (such as a stick, knife, or gun). It is not a physical attack when two students of about the same strength or power choose to fight each other.

16) During the past 12 months, how many times were you physically attacked?
a) 0 times
b) 1 times
c) 2 or 3 times
d) 4 or 5 times
e) 6 or 7 times
f) 8 or 9 times
g) 10 or 11 times
h) 12 or more times

The next question asks about physical fights. A physical fight occurs when two students of about the same strength or power choose to fight each other.

17) During the past 12 months, how many times were you in a physical fight?
a) 0 times
b) 1 times
c) 2 or 3 times
d) 4 or 5 times
e) 6 or 7 times
f) 8 or 9 times
g) 10 or 11 times
h) 12 or more times

The next questions ask about serious injuries that happened to you. An injury is serious when it makes you miss at least one full day of usual activities (such as school, sports, or a job) or requires treatment by a doctor or nurse.

18) During the past 12 months, how many times were you seriously injured?
a) 0 times
b) 1 times
c) 2 or 3 times
d) 4 or 5 times
e) 6 or 7 times
f) 8 or 9 times 
g) 10 or 11 times

h) 12 or more times

19) During the past 12 months, what was the most serious injury that happened to you?

a) I was not seriously injured during the past 12 months

b) I had a broken bone or a dislocated joint

c) I had a cut or stab wound

d) I had a concussion or other head or neck injury, was knocked out, or could not breathe

e) I had a gunshot wound

f) I had a bad burn

g) I was poisoned or took too much of a drug

h) Something else happened to me

20) During the past 12 months, what was the major cause of the most serious injury that happened to you?

a) I was not seriously injured during the past 12 months

b) I was in a motor vehicle accident or hit by a motor vehicle

c) I fell

d) Something fell on me or hit me

e) I was attacked or abused or was fighting with someone

f) I was in a fire or too near a flame or something hot

g) I inhaled or swallowed something bad for me

h) Something else caused my injury

The next questions ask about bullying. Bullying occurs when a student or group of students say or do bad and unpleasant things to another student. It is also bullying when a student is teased a lot in an unpleasant way or when a student is left out of things on purpose. It is not bullying when two students of about the same strength or power argue or fight or when teasing is done in a friendly and fun way.

21) During the past 30 days, on how many days were you bullied?
a) 0 day
b) 1 or 2 days
c) 3 to 5 days
d) 6 to 9 days
e) 10 to 19 days
f) 20 to 29 days
g) All 30 days

22) During the past 30 days, how were you bullied most often?

a) I was not bullied during the past 30 days

b) I was hit, kicked, pushed, shoved around, or locked indoors

c) I was made fun of because of my race, nationality, or color

d) I was made fun of because of my religion

e) I was made fun of with sexual jokes, comments, or gestures 
f) I was left out of activities on purpose or completely ignored

g) I was made fun of because of how my body or face looks

h) I was bullied in some other way

The next questions ask about your feelings and friendships.

23) During the past 12 months, how often have you felt lonely?

a) Never

b) Rarely

c) Sometimes

d) Most of the time

e) Always

24) During the past 12 months, how often have you been so worried about something that you could not sleep at night?
a) Never
b) Rarely
c) Sometimes
d) Most of the time
e) Always

25) During the past 12 months, did you ever consider attempting suicide?

a) Yes

b) No

26) During the past 12 months, did you ever seriously consider attempting suicide?

a) Yes

b) No

27) During the past 12 months, how many times did you actually attempt suicide?
a) 0 times
b) 1 time
c) 2 or 3 times
d) 4 or 5 times
e) 6 or more times
a) 0 times
b) 1 time
c) 2 times
d) 3 or more times

28) How many close friends do you have?

The next questions ask about cigarette and other tobacco use.

29) How old were you when you first tried a cigarette?

a) I have never smoked cigarettes

b) 7 years old or younger

c) 8 or 9 years old

d) 10 or 11 years old

e) 12 or 13 years old 
f) 14 or 15 years old

g) 16 or 17 years old

h) 18 years old or older

30) During the past 30 days, on how many days did you smoke cigarettes?

a) 0 days

b) 1 or 2 days

c) 3 to 5 days

d) 6 to 9 days

e) 10 to19 days

f) 20 to 29 days

g) All days

31) During the past 30 days, on how many days did you use any tobacco products other than cigarettes, such as pipe, rolled tobacco leaves, snuff powder or chewing tobacco leaves?
a) 0 days
b) 1 or 2 days
c) 3 to 5 days
d) 6 to 9 days
e) 10 to19 days
f) 20 to 29 days

32) During the past 12 months, have you ever tried to stop smoking cigarettes?

a) I have never smoked cigarettes

b) I did not smoke cigarettes during the past 12 months

c) Yes

d) No

33) During the past 7 days, on how many days have people smoked in your presence?
a) 0 days
b) 1 or 2 days
c) 3 to 4 days
d) 5 to 6 days
e) All days
a) Neither
b) My father or male guardian
c) My mother or female guardian
d) Both
e) I do not know

34) Which of your parents or guardians use any form of tobacco?

The next questions ask about drinking alcohol as sodabi, atan, tchoukoutou, Drinking alcohol does not include drinking a few sips of wine for religious purposes. A "drink" is a glass of wine, a bottle of beer, a small glass of liquor, or a mixed drink. 
35) How old were you when you had your first drink of alcohol other than a few sips?

a) have never had a drink of alcohol other than a few sips

b) 7 years old or younger

c) 8 or 9 years old

d) 10 or 11 years old

e) 12 or 13 years old

f) 14 or 15 years old

g) 16 or 17 years old

h) 18 years old or older

36) During the past 30 days, on how many days did you have at least one drink containing alcohol?
a) 0 das
b) 1 or 2 days)
c) 3 to 5 days
d) 6 to 9 days
e) 10 to 19 days
f) 20 to 29 days
g) All 30 days

37) During the past 30 days, on the days you drank alcohol, how many drinks did you usually drink per day?
a) I did not drink alcohol during the past 30 days
b) Less than one drink
c) 1 drink
d) 2 drinks
e) 3 drinks
f) 4 drinks
g) 5 or more drinks

38) During the past 30 days, how did you usually get the alcohol you drank? SELECT ONLY ONE RESPONSE.
a) I did not drink alcohol during the past 30 days
b) I bought it in a store, shop, or from a street vendor
c) I gave someone else money to buy it for me
d) I got it from my friends
e) I got it from my family
f) I stole it or got it without permission
g) I got it some other way

Staggering when walking, not being able to speak right, and throwing up are some signs of being really drunk.

39) During your life, how many times did you drink so much alcohol that you were really drunk?
a) 0 times
b) 1 or 2 times
c) 3 to 9 times 
d) 10 or more times

40) During your life, how many times have you got into trouble with your family or friends, missed school, or got into fights, as a result of drinking alcohol?
a) 0 times
b) 1 or 2 times
c) 3 to 9 times
d) 10 or more times

The next questions ask about drug use. This includes using marijuana, amphetamines, cocaine, inhalants, cannabis

41) How old were you when you first used drugs?

a) I have never used drugs

b) 7 years old or younger

c) 8 or 9 years old

d) 10 or 11 years old

e) 12 or 13 years old

f) 14 or 15 years old

g) 16 or 17 years old

h) 18 years old or older

42) How many times in your life did you take cannabis?

a) 0 times

b) 1 or 2 times

c) 3 to 9 times

d) 10 to 19 times

e) 20 times and more

43) In the last 30 days, how many times have you taken cannabis?

a) 0 times

b) 1 or 2 times

c) 3 to 9 times

d) 10 to 19 fois

e) 20 or more times

44) How many times in your life did you take amphetamine (also called stimulants, products not prescribed by a doctor)?
a) 0 times
b) 1 or 2 times
c) 3 to 9 times
d) 10 to 19 times
e) 20 or more times

The next questions ask about sexual intercourse.

45) Have you ever had sexual intercourse?

a) Yes

b) No

46) How old were you when you had sexual intercourse for the first time?

a) Je n'ai jamais eu de relation sexuelle 
b) 11 years old or younger

c) 12 years old

d) 13 years old

e) 14 years old

f) 15 years old

g) 16 or 17 years old

h) 18 years old or older

47) During your life, with how many people have you had sexual intercourse?

a) I have never had sexual intercourse

b) 1 person

c) 2 people

d) 3 people

e) 4 people

f) 5 people

g) 6 or more people

48) The last time you had sexual intercourse, did you or your partner use a condom?

a) I have never had sexual intercourse

b) Yes

c) No

49) The last time you had sexual intercourse, did you or your partner use any other method of birth control, such as withdrawal, rhythm (safe time), birth control pills, or any other method to prevent pregnancy?
a) I have never had sexual intercourse
b) Yes
c) No
d) I don't know

50) How often do you or your partner use a condom or condom when you have sex?
a) I have never had sexual intercourse
b) Never
c) Rarely
d) Sometimes
e) Most of the time
f) Always

51) With whom do you have sexual intercourse?
a) I have never had sexual intercourse
b) Only women
c) Only men
d) Women and men

52) Last time you have sexual intercourse, did you drink alcohol or take various drugs before?

a) I have never had sexual intercourse 
b) Yes

c) No

53) How many times have you been pregnant (ONLY FOR GIRLS)?

a) 0 times

b) 1 time

c) 2 or more times

d) Don't know

The next questions ask about physical activity. Physical activity is any activity that increases your heart rate and makes you breathe hard. Physical activity can be done in sports, playing with friends, or walking to school. Some examples of physical activity are running, fast walking, biking, dancing, football, and others.

54) During the past 7 days, on how many days were you physically active for a total of at least 60 minutes per day? ADD UP ALL THE TIME YOU SPENT IN ANY KIND OF PHYSICAL ACTIVITY EACH DAY.
a) 0 days
b) 1 day
c) 2 days $s$
d) 3 days
e) 4 days
f) 5 days
g) 6 days
h) 7 days

55) During this school year, on how many days did you go to physical education (PE) class each week?
a) 0 days
b) 1 day
c) 2 days
d) 3 days
e) 4 days
f) 5 or more days

The next question asks about the time you spend mostly sitting when you are not in school or doing homework.

56) How much time do you spend during a typical or usual day sitting and watching television, playing computer games, talking with friends, or doing other sitting activities, such as playing cards or playing domino?

a) Less than 4 hours per day

b) More than 4 hours per day

The next questions ask about your experiences at school and at home.

57) During the past 30 days, on how many days did you miss classes or school without permission?
a) 0 days
b) 1 or 2 days 

c) 3 to 5 days
d) 6 to 9 days
e) 10 or more days

58) During the past 30 days, how often were most of the students in your school kind and helpful?
a) Never
b) Rarely
c) Sometimes
d) Most of the time

e) Always

59) During the past 30 days, how often did your parents or guardians check to see if your homework was done?
a) Never
b) Rarely
c) Sometimes
d) Most of the time
e) Always
60) During the past 30 days, how often did your parents or guardians understand your problems and worries?
a) Never
b) Rarely
c) Sometimes
d) Most of the time
e) Always

61) During the past 30 days, how often did your parents or guardians really know what you were doing with your free time?
a) Never
b) Rarely
c) Sometimes
d) Most of the time
e) Always

62) During the past 30 days, how often did your parents or guardians go through your things without your approval?
a) Never
b) Rarely
c) Sometimes
d) Most of the time
e) Always
63) Department
a) Alibori
b) Atacora
c) Atlantique
d) Borgou 
e) Collines

f) Couffo

g) Donga

h) Littoral

i) Mono

j) Ouémé

k) Plateau

l) Zou

64) Areas of résidence

a) Rural

b) Urban

The next questions ask about abortion and masturbation

65) How many times have you had a proposed abortion?

a) 0 times

b) 1 time

c) 2 times ans more

66) Have you ever been able to masturbate?

a) Yes

b) No

67) In the last 12 months, how many times have you ever been able to masturbate?
a) 0 times
b) 1 time
c) 2 or 3 times
d) 4 to 9 times
e) 10 to 29 times
f) 30 times and more 